\section{EMBRYRIDDLE}

Aeronautical University

SCHOLARLY COMMONS
Journal of Aviation/Aerospace

Education \& Research

Volume 8

Number 1 JAAER Fall 1997

Article 9

Fall 1997

\title{
Teaching Landings by the Numbers: Quantifying the Visual Approach and Landing
}

Charles (Chuck) R. Moren

morenc@erau.edu

Follow this and additional works at: https://commons.erau.edu/jaaer

\section{Scholarly Commons Citation}

Moren, C. R. (1997). Teaching Landings by the Numbers: Quantifying the Visual Approach and Landing. Journal of Aviation/Aerospace Education \& Research, 8(1). https://doi.org/10.15394/jaaer.1997.1217

This Article is brought to you for free and open access by the Journals at Scholarly Commons. It has been accepted for inclusion in Journal of Aviation/Aerospace Education \& Research by an authorized administrator of Scholarly Commons. For more information, please contact commons@erau.edu. 


\title{
TEACHING LANDINGS BY THE NUMBERS: QUANTIFYING THE VISUAL APPROACH AND LANDING
}

\author{
Charles R. "Chuck" Moren
}

We have all heard it said that a good landing requires a good approach. But what can we do to teach our students to make good approaches? What techniques can we emphasize to ensure that the variables that affect each approach -- speed, approach angle, and runway alignment -- are controlled in such a way that the pilot arrives at the proper position and at an appropriate speed that allows a smooth transition to the touchdown attitude and contact with the runway at an acceptable point in the touchdown zone? The key to teaching students to land successfully is to consistently execute approaches that ensure that the aircraft arrives at a predetermined point from which the transition to the touchdown attitude can begin. This paper will explain one method of flying good approaches by the numbers -- numbers that will help quantify some of the variables that make the execution of the visual approach and landing such a challenge to our students. Included are several other important techniques that support and enhance the information provided.

\section{INTRODUCTION}

The first thing a new pilot wants to do is to try a landing. Most pre-solo students can hardly wait to get in the pattern. Landing the airplane without the instructor's assistance is the students' proof to themselves that they can fly airplanes and that they are now real pilots.

The landing is seen by many as the most challenging maneuver the pilot must perform. In many ways, those who accept the approach and landing maneuver as proof of a pilot's abilities are correct. The approach and landing maneuver is evaluated by airline passengers, by those spending their lunch hour parked at the end of the runway watching the airplanes land, and, most importantly, by those who evaluate pilot performance as part of a flight check or flight review. Pilots are expected to be masters of their aircraft, with the safe outcome of any maneuver never seriously in doubt. Pilots are required to demonstrate planning, smoothness, good judgment, and accuracy -- and nothing requires those skills as much as a good approach and landing.

For those who might point out that a partial-panel, circling, non-directional beacon (NDB) approach on a dark and stormy night might also be a challenge -- I agree. Any flight maneuver can be the ultimate video game with real-life consequences, but the visual approach and landing gives us a daily collection of challenges.

\section{THE APPROACH WITH NO WIND}

Where do we turn final? If we accept the premise that we need to teach new pilots techniques that they can carry with them throughout their careers, then we must accept the $3^{\circ}$ approach angle, applicable to visual approach slope indicators (VASI) and to instrument landing systems (ILS), as the standard.

FAA Advisory Circular 61-47A (1979) recommends that when a VASI is available we should use the indications of the VASI to help our students acquire the visual cues necessary to execute visual approaches at a consistent angle.

One way to execute approaches at a consistent angle is to establish an imaginary approach window. This approach window is a point in space located on the desired approach path at a predetermined distance from the point of intended landing. If we establish this window at the point where we normally turn final, then we can use an altitude of 500 feet above field elevation (AFE). Our goal then is to pass through this window on every normal approach. We would then be starting our final approach at the same angle every time. If modification to the normal approach is necessary -- for example, extending our downwind to follow traffic -- then our goal is to adjust our extended pattern to eventually pass through this same approach window. 
If we begin our final approach segment at 500 feet AFE, we can compute the length of our final approach (the desired distance from the approach window to our point of intended landing) by multiplying our altitude (500 feet AFE) by the tangent of $87^{\circ}$, the opposite angle of $3^{\circ}$. So, 500 feet $x \tan 87^{\circ}=9,541$ feet or 1.6 nautical miles (1.8 statute miles). If we are established on the final approach at 500 feet AFE, 1.6 miles from our point of intended landing, and draw an imaginary line from the aircraft to the runway, we will have established our ideal (and imaginary) approach path. From that point the only task is to maneuver the aircraft along this imaginary line at a typical final-approach speed of 65 knots, consuming exactly 89 seconds of our typical 1.2 -hour dual-training flight.

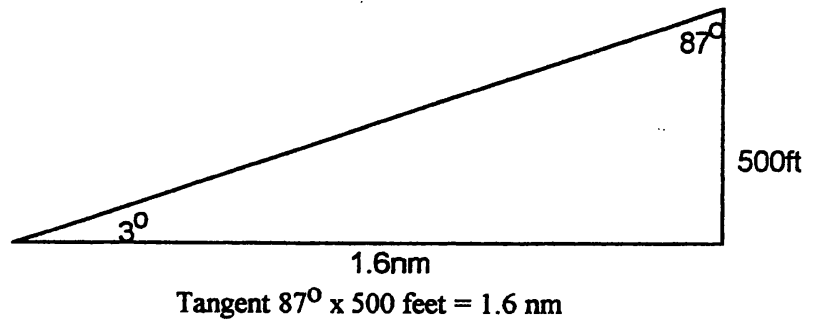

Although the use of the vertical speed indicator (VSI) as a primary instrument during the visual approach is definitely not recommended, we could determine our descent rate in feet per minute in advance. This is in fact an important part of teaching ILS approach procedures. At an approach speed of 65 knots, applying the formula Speed $x 5.3$ will result in an approximate rate of $345 \mathrm{fpm}$ to maintain a $3^{\circ}$ approach path.

So, turn final at $500 \mathrm{AFE}$ at 65 knots. Assuming level terrain, no wind, and no vertical air movement, your imaginary $3^{\circ}$ approach path will intersect the runway at your point of intended landing.

\section{THE LANDING WITH NO WIND}

The transition to the touchdown attitude is commonly referred to as a flare.

The Flight Training Handbook describes the flare, or roundout, as:

... the smooth transition from a normal approach to a landing attitude. When the airplane, in a normal descent, approaches within what appears to be about 10 to 20 feet above the ground, the roundout or flare should be started, and once started should be a continuous process until the airplane touches down on the ground. (FAA, 1980, p. 99)

Students should be taught during preflight briefings that the transition to touchdown attitude is a controlled maneuver requiring the proper coordination of pitch and power changes; the maneuver should be not oversimplified by instructors with such commands as "now!" or "flare!" or even "I've got it!"

The transition begins with an almost simultaneous decrease in power and increase in angle of attack (pitch attitude). If we are lucky enough to be on a perfectly stabilized approach, at the desired airspeed, we still must prevent the aircraft from impacting the ground at $\mathbf{3 0 0}$ to $400 \mathrm{fpm}$. Somehow we must decrease the rate of descent to almost zero just as the landing gear contacts the runway. We also want to decrease our approach speed to touchdown speed. In most cases touchdown speed is just above stall. Fortunately, this is easy. As a result of increasing the angle of attack to decrease the rate of descent, the increased drag causes our speed to decrease. The hard part, of course, is the timing.

\section{Ground Effect}

As the aircraft descends to within approximately one-half of the wingspan of the ground, the induced drag is noticeably decreased. Induced drag is created by the wingtip vortices that result from creating lift. When we create lift, we create a low-pressure area above the wing. The high pressure below the wind tends to wrap around the wingtip, searching for the low-pressure area, creating a spiraling effect. Within a distance of one wingspan of the ground these rotational tendencies are blocked by the ground. The resultant decrease in drag is perceived by the pilot as an increase in lift. This is largely responsible for the phenomenon we call float. The pilot can anticipate the decrease in drag and compensate for it during the transition to the touchdown attitude by increasing the rate that power is decreased as we enter ground effect.

\section{THE APPROACH AND LANDING WTTH WIND}

For discussion, let's assume a $10-\mathrm{knot}$ wind at a $45^{\circ}$ angle to the runway and a $65-\mathrm{knot}$ indicated airspeed. 
The head wind component would be 8 knots and the ground speed 58 knots. If we recomputed the rate of descent, we would find that the rate required to maintain a $3^{\circ}$ path would decrease from 345 to $307 \mathrm{fpm}$. To decrease the rate of descent we must increase the angle of attack by pitching up. How much pitch up? One degree of pitch change will result in a change in rate approximately equal to true air speed (in nautical miles per minute) multiplied by 100 . With an approach speed of 65 knots (approximately 1.08 miles per minute), a one-degree pitch change would result in a rate change of $108 \mathrm{fpm}$. In our example a pitch change of $1 / 3$ of 1 degree would be necessary. We then will need to increase power to prevent our desired approach speed from decreasing due to the increase in induced drag. It will help if the student understands that $100 \mathrm{rpm}$ or 1 inch of manifold pressure equals about 5 knots.

There are two methods to correct for crosswind and maintain an approach path that is aligned with the extended runway centerline. The first method is to establish a wind-correction angle (crab angle) similar to the wind-correction angle used for cross-country navigation. In our example this would be a $6^{\circ}$ angle. Although this method is an excellent way to maintain a ground track aligned with the runway, the aircraft cannot touch down with a side load on the landing gear; therefore, at some point before touchdown the aircraft's longitudinal angle must be aligned with the runway centerline.

The second method is the wing-low method or side slip. A side slip is established by banking the aircraft and applying opposite rudder. When we bank the aircraft we establish a horizontal composite of lift. This horizontal component would normally cause the aircraft to turn in the direction of the bank. During an approach we can bank the aircraft to establish a horizontal component of lift, equal and opposite to the crosswind component, and at the same time prevent the aircraft from turning by applying opposite rudder (cross controlling). Unfortunately, this configuration causes a decrease in the vertical component of lift and an increase in drag. To prevent an increase in the rate of descent and flight-path angle, an increase in angle of attack is required. This increase in angle of attack/lift/induced drag requires an increase in power to prevent a decrease in approach speed.

These two methods can be used in combination. First a crab to correct for wind during the downwind, base, and initial final-approach segments, and then a side slip as the transition to the touchdown attitude begins. This combination method should be used because strong crosswinds cannot be handled with the wing-low method alone. Rudder effectiveness determines the maximum crosswind component that can be compensated for with a side slip or, more accurately, the horizontal component of lift created by a side slip. Most airplanes cannot handle crosswinds with a side slip alone if the crosswind is in excess of $0.2 \mathrm{~V}_{\mathrm{so}}$, which for most light aircraft is about 10 knots. Strong crosswinds require the use of a crab angle on final approach combined with a transition to a side slip by the use of a de-crab maneuver just before touchdown. Because most airplanes at normal approach speed require a side-slip bank angle of approximately one-half of the crab angle required on final approach, a precise de-crab maneuver can be accomplished by yawing (with the rudder) to align the longitudinal axis with the runway centerline, while establishing a bank angle into the wind equal to one-half of the previous crab angle to compensate for any movement away from the runway centerline caused by the crosswind component. As in our example, if a $6^{\circ} \mathrm{crab}$ angle to the left is required on final, at the beginning of the transition to the touchdown attitude the longitudinal axis must be yawed $6^{\circ}$ to the right while a $3^{\circ}$ left bank is established. Right rudder, left aileron. In other words, crossed controls -- a slip.

As the transition continues and the altitude above. the runway decreases, surface friction reduces the wind speed and therefore the crosswind component. This reduced crosswind component requires removing approximately half of the bank angle and reducing the rudder pressure to maintain the alignment of the longitudinal axis and the runway centerline as the aircraft approaches touchdown. This alignment prevents any side load on the landing gear at touchdown.

A side slip should not be used during the initial final-approach segment. Using a side slip to correct for strong winds at altitudes well above the friction level 
requires large side-slip bank angles, which cause a significant decrease in the vertical component of lift, large drag increases, possible loss of airspeed (if power is not added appropriately), and discomfort for the passengers as they hang in their seat belts. In transport-category aircraft a side slip (wing-low method) before transition to the touchdown attitude cannot be used due to spoiler deflection, causing additional drag and reduced lift and further increasing sink rate. Transport-category airplanes have touchdown bank-angle limitations due to long wingspans and the possibility of engine-nacelle contact with the runway, making the ability to shift to a precise bank attitude at touchdown an absolute necessity. Our students will be flying large aircraft in the future and it is easier for them to learn good techniques now than it will be for them to change their habits later in their careers.

\section{THE LANDING ROLL}

The landing is not complete until the aircraft slows to taxi speed and safely exits the runway. We must not allow our students to stop flying the aircraft until the chocks are in place. Most new students tend to stop controlling the aircraft immediately after touchdown. At the time of touchdown, if the aircraft is held in a proper touchdown attitude, the elevator will be deflected up -- in most cases, all the way up. If the elevator is allowed to move to a down position at touchdown, the air flow over the elevator will tend to lift the tail, decreasing the angle of attack and shifting the center of pressure rearward. Assuming a tricycle gear, the nose wheel will be supporting a larger-than-normal percentage of the aircraft weight. The elevator may have sufficient force to lift the main gear off the runway. This situation is known as a wheelbarrow landing. Those who have pushed a loaded wheelbarrow know how unstable it is and how difficult it is to prevent the wheelbarrow from spilling the load to one side. If the aircraft is allowed to wheelbarrow, directional control will be lost if any outside force is applied to the aircraft. The most common outside force is a crosswind. In that case, the aircraft most likely will leave the paved surface of the runway and stop in the grass. If the propeller is not bent on a runway light or sign, close inspection might reveal that it made contact with the pavement.
It is vital that our students understand that the only safe landing roll is one that is made with most of the weight of the aircraft on the main landing gear. The elevator should be positioned in the up (yoke back/nose up) elevator position during the duration of the landing roll. As the aircraft slows, the ailerons should be deflected more and more into the wind until full aileron deflection is reached as the aircraft slows to a normal taxi speed. At the completion of the landing roll the controls should be positioned for taxi. In the quartering head wind example given previously, we should have the ailerons turned into the wind and the elevator displaced as recommended by the manufacturer.

\section{CONCLUSION}

If our students are to execute good landings, they must learn to adjust their approaches so that they consistently pass through the approach window at the desired approach speed, at 500 feet AFE, 1.6 miles from the point of intended landing.

The proper time to quantify the approach-and-landing maneuver for our students is during a detailed preflight briefing. You must establish a shared mental model with your students before you can expect them to fly the aircraft the way you want them to.

Eventually our students must learn to modify the standard approach to compensate for wind, obstructions, other traffic, nonstandard approach procedures, and ultimately even a circle-to-land from a partial-panel NDB approach. Air-traffic control will ask them to keep their speed up or to slow down to follow slower traffic. And we must teach our students to correct approaches that for whatever reason are high and fast or low and slow. If our students know what a standard approach is, they can better judge which approaches can be corrected, which can be safely modified, and which should end in a go-around and not a landing. Emphasize to your students the value of the decision to discontinue any approach that is not stabilized.

The cues that we have learned over hundreds or even thousands of hours are new and somewhat confusing to our students. If we recall that, according to the Aviation Instructor's Handbook (FAA, 1977, p. 6), the primary job of the flight instructor is evoking insight and "grouping perceptions into meaningful wholes," then we will see 
that our job is to ensure that our students understand the variables that affect their landings.

Most of all, we should be patient, because we too were once young pilots challenged by the visual approach and landing. $\square$

Charles R. "Chuck" Moren earned master's and bachelor's degrees in Aeronautical Science and an associate degree in Aviation Management, all from Embry-Riddle Aeronautical University. He holds an Airline Transport Pilot Certificate with a Boeing 737 type rating and a Certified Flight Instructor Certificate with all fixed-wing ratings. Moren is an associate professor in the Aeronautical Science Department at Embry-Riddle.

\section{REFERENCES}

Federal Aviation Administration. (1977).Aviation instructor's handbook (AC60-14). Washington, DC: U.S. Government Printing Office.

Federal Aviation Administration. (1979). Use of approach slope indicators for pilot training (AC 61-47A). Washington, DC: U.S. Government Printing Office.

Federal Aviation Administration. (1980). Flight training handbook (AC 61-21A). Washington, DC: U.S. Government Printing Office. 